\title{
INFLUENCE OF AIR VELOCITY ON DRYING DYNAMICS OF ALFALFA
}

\author{
Aivars Aboltins ${ }^{1}$, Pavel Kic ${ }^{2}$ \\ ${ }^{1}$ Latvia University of Life Sciences and Technologies, Latvia; \\ ${ }^{2}$ Czech University of Life Sciences Prague, Czech Republic \\ aivars.aboltins@inbox.lv, kic@tf.czu.cz
}

\begin{abstract}
Alfalfa is widely used as feed for animals, and preservation of fodder is an important problem. This paper contains the experimental and theoretical investigations of alfalfa (Medicago sativa) drying by forced convection. This research is focused on verification of the influence of different air velocities on the drying process of alfalfa in thin layer in mild temperatures $\left(22^{\circ} \mathrm{C}\right)$ and rather high relative humidity of air $(70 \%)$. The initial moisture content of the material was determined by the gravimetric method using the hot air drying in the electric oven. Special device for convection drying with air flow passing through the material from the bottom through supporting trays with a sieve (dimensions of mesh $3 \times 4 \mathrm{~mm}$ ) by constant temperature was used for drying experiments, when the air velocity $0.7 \mathrm{~m} \cdot \mathrm{s}^{-1}, 1.0 \mathrm{~m} \cdot \mathrm{s}^{-1}, 1.2 \mathrm{~m} \cdot \mathrm{s}^{-1}$ and $2.0 \mathrm{~m} \cdot \mathrm{s}^{-1}$. Changes of alfalfa samples moisture were determined from the measured values of weight using the gravimetric method. The most preferable form of the alfalfa drying coefficient $K(t)$ with forced air was power expression. Using the experimental data and the mathematical model of the thin layer drying process, it is possible to determine the unknown parameters at each speed of the drying agent. The theoretical results are compared with the experimental results and the average difference was lower than $6 \%$. The biggest difference was observed at lower air speeds and at the initial stage of the process. Using the experimental results relationships between the air velocity and the parameters included in the function of the drying coefficient were determined. This research allows theoretically predicting the drying process depending on the air velocity.
\end{abstract}

Keywords: forced drying, drying, coefficient, alfalfa.

\section{Introduction}

Alfalfa (Medicago sativa) is widely used as animal feed, which has high crude protein content and energy, reducing the needs of supplements in rations. The intake potential allows it for greater use in rations of high-producing dairy cows. Fresh alfalfa contains about $80 \%$ moisture. Good hay preservation depends primarily on handling and harvest management. The drying rate, mechanical handling of the forage and the moisture content at baling all affect the quality of the hay.

Alfalfa, more than most other crop species, has the ability to intercept nitrates from the soil. It has an outstanding ability to absorb nitrate from the soil solution [1].

One of the best ways to process alfalfa is haylage or silage. The round bales is a popular way how to process this plant. During drying hay, there could be a problem with moisture and weather conditions (rain). These problems can be associated with quality losses, and other losses can arise, if we store insufficiently dried hay.

If we understand and use the biology and physics of forage drying properly, not only does the hay dry faster and have less chance of being rained on, but the total digestible nutrients of the harvested forage are higher. Hay is a primary source of livestock feed during winter. The storage conditions affect hay losses and quality changes. Total loss for quality hay stored outside on the ground could be 25-30\%, while losses for animal feeding could reach 40 percent [2]. One of the factors of storage losses is the moisture content at baling and the time of storage [2].

Hay with less than $15 \%$ moisture is relatively stable, and little respiration occurs. Alfalfa hay baled at $16 \%$ moisture can be expected to lose $3.5 \%$ of its dry matter (mass) in four months. Anderson et al. showed that storage dry matter losses average three percent of harvested dry matter weight for indoor storage and 14 percent for outside storage [3]. Dry matter changes in alfalfa hay during 6-months storage were $5 \%$ loss in hay baled from 11 to $20 \%$ moisture [4]. Hay baled at $13 \%$ moisture with high leaf shatter will not decrease in quality as much as hay baled at $20 \%$ moisture with little leaf shatter.

Higher moisture content ensures mould growth and other microbiological activity. In hay containing more moisture, microbial respiration causes the hay to heat during the first month of storage. The amount of heating and the associated loss increase with the moisture content. Dry matter losses during the first month of storage change from $1 \%$ in hay of $15 \%$ moisture to $8 \%$ in $30 \%$ moisture hay [5]. The main aspects of losses and the moisture content importance are shown in [6]. 
For decreased drying time a mower-conditioner for cut should be used [7]. Hay bale losses are functions of hay moisture, temperature and how long the hay is exposed to these conditions [8].

To develop recommendations for cutting fodder crops and drying, based on the weather conditions, it

can be useful to apply mathematical modelling. Important problems for future are the energy saving problem in the drying process.

A drying model can estimate the moisture content of fodder crops as a function of time for given drying conditions. The predictive model and uses of the weather conditions (air temperature, wind speed, global radiation) are shown in [9]. The drying process of harvested grass was evaluated using numerical approaches in [10]. Thin-layer drying characteristics of some herbal leaves are investigated experimentally $[11 ; 12]$. There is some research about dehydration of green alfalfa at high temperatures [13] , chopped alfalfa in the rotary dryer [14] and thin layer [15]

The aim of this study is to determine the function of the drying coefficient $K(t)$ of alfalfa for changing the air velocities at constant drying temperature.

\section{Materials and methods}

The laboratory measurements were carried out at the Faculty of Engineering of the Czech University of Life Sciences Prague during the weather conditions in August. The technical equipment used in the experiments was the forced convection system [16; 17]. The velocities for each chamber were $0.7 \mathrm{~m} \cdot \mathrm{s}^{-1}, 1 \mathrm{~m} \cdot \mathrm{s}^{-1}, 1.2 \mathrm{~m} \cdot \mathrm{s}^{-1}$ and $2.0 \mathrm{~m} \cdot \mathrm{s}^{-1}$ and the results were compared with natural convection drying by the same temperature.

Each chamber is independent and allows for a different flow rate of air velocities, Fig. 1. Samples for each measurement were inserted into chambers on asieve tray with mesh $3 \times 4 \mathrm{~mm}$ of total area approximately $204 \mathrm{~cm}^{2}$. The airflow for drying of the samples is delivered by the fan of diameter $120 \mathrm{~mm}$ and controlled by the fan revolutions, Fig. 2.

Alfalfa samples were cut into pieces of $2-5 \mathrm{~cm}$ length and placed in a layer of about $5 \mathrm{~cm}$ on the sieve trays. Weight of the samples on the tray was approximately $120 \mathrm{~g}$.

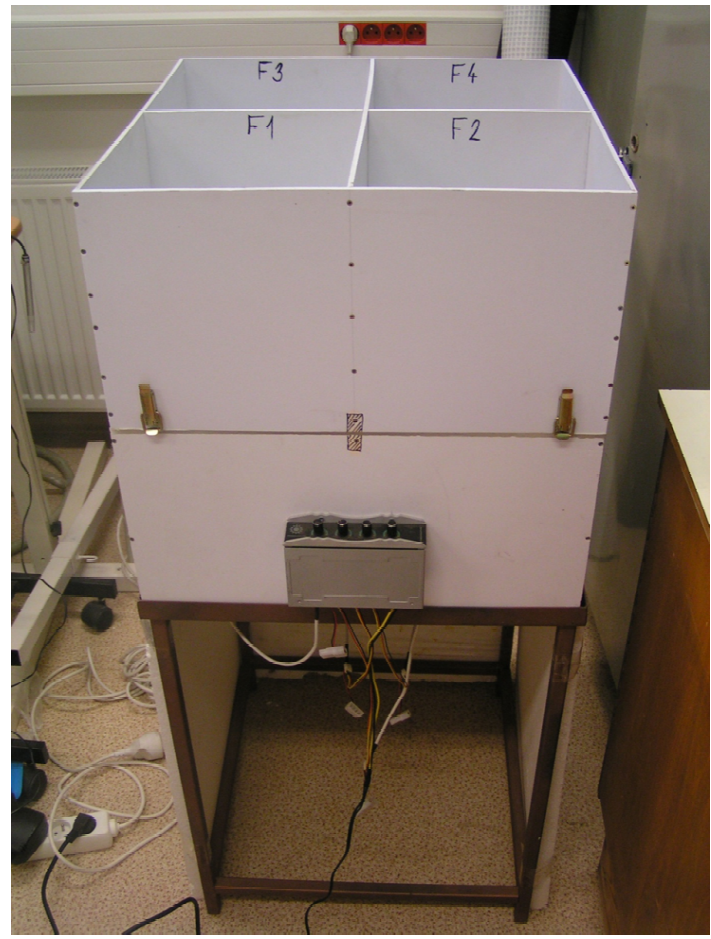

Fig. 1 Apparatus used for drying

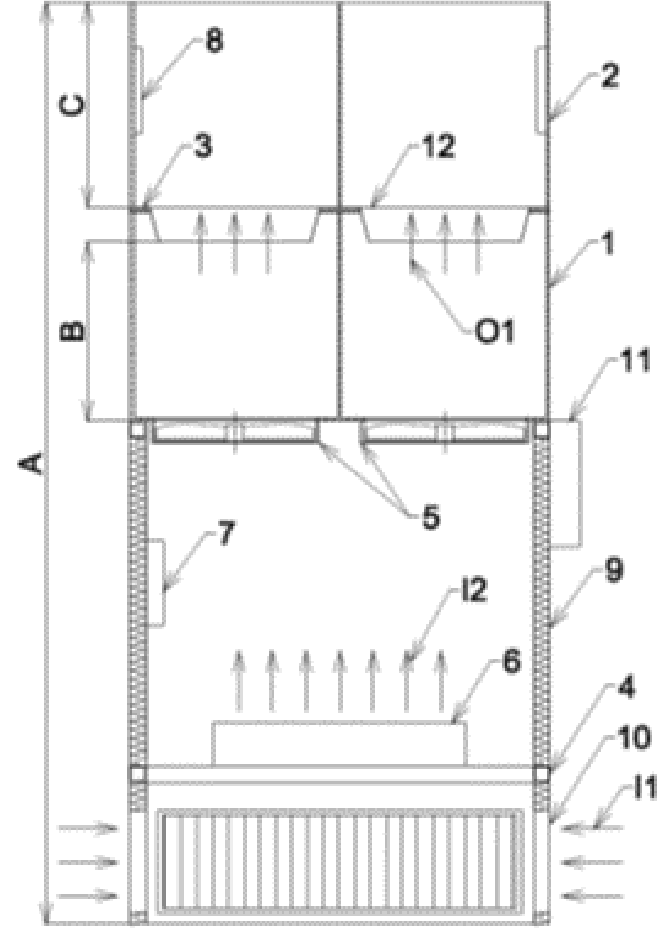

Fig. 2 Drying equipment functioning scheme [15] 
On Fig. 2: A - overall height; $\mathrm{B}$ - height of lower chamber; $\mathrm{C}$ - height of upper chamber. 1 lower drying chamber; 2 - upper drying chamber; 3 - underlay; 4 - carcass; 5 - fans; 6 - air heater; 7 , 8 - sensors; 9 - thermal insulation; 10 - inlet air flow; 11 - control panel; 12 - perforated tray with drying material; I1 - ambient inlet air; O1 - air movement through the drying material.

Equipment: Anemometer CFM 8901 Master (Hygrotec Messentechnik GmbH, Germany) with resolution $0.01 \mathrm{~m} \cdot \mathrm{s}^{-1}$ and accuracy $\pm 2 \%$ of final value was used for measuring the air velocity. The sensor FHA646-E1C was used for measuring the humidity and air temperature. The logger ALMEMO 2690-8 (Ahlborn GmbH, Germany) receives the sensor measurements. The measured average temperature of the drying air was $27 \pm 0.7^{\circ} \mathrm{C}$ and relative humidity $49 \pm 1.8 \%$.

During the first $30 \mathrm{~min}$ of drying the samples were weighted every $10 \mathrm{~min}$, the next hour every 15 min, the next 2 hours every 30 min and then every 60 min.

The dry matter $(\mathrm{DM})$ content in alfalfa was detected by gravimetric measurement using an MEMERT UNB-200 (MEMMERT GmbH + Co. KG, Germany) air oven under temperature $103^{\circ} \mathrm{C}$. During regular time intervals the samples were weighed on a Kern 440-35N laboratory balance. The total drying time was adjusted to the need for determination of the equilibrium moisture.

\section{Results and discussion}

Based on the results of the measurements water loses and dry weight of the original sample volume for all air velocities are calculated. The partial goal is to determine the drying coefficient $K(t)$ that is obtained by fitting the values of each measurement into the equation (1).

$$
K(t)=\frac{-\ln \left|\frac{m-m_{d}}{m_{s}-m_{d}}\right|}{t},
$$

where $K(t)$ - drying coefficient;

$m$ - weight of alfalfa samples during drying, $g$;

$m_{d}-$ weight of dry matter, g;

$m_{s}-$ alfalfa samples weight at the beginning of drying, g;

$t$ - drying time, $\mathrm{h}$.

The drying coefficient $K(t)$ values are determined and approximated according to [18]. For the best approximation of these data function (2) is chosen.

$$
K(t)=a t^{b},
$$

where $a, b-$ constants that characterize experimental conditions.

For each drying air velocity $a$ and $b$ values are determined from (2). These results are shown in Table 1.

Coefficients $a, b$ values dependence on air velocity

Table 1

\begin{tabular}{|c|c|c|c|}
\hline $\begin{array}{c}\text { Air velocity, } \\
\mathbf{m} \cdot \mathbf{s}^{-1}\end{array}$ & $\boldsymbol{a}$ & $\boldsymbol{b}$ & $\boldsymbol{R}^{2}$ \\
\hline 0.01 & 0.0268 & -0.0970 & 0.6155 \\
\hline 0.70 & 0.2000 & -0.2494 & 0.9186 \\
\hline 1.00 & 0.2100 & -0.2745 & 0.9523 \\
\hline 1.20 & 0.1690 & -0.3093 & 0.9930 \\
\hline 2.00 & 0.1720 & -0.3037 & 0.9910 \\
\hline
\end{tabular}

Table 1 shows that the coefficient of determination $R^{2}$ for air velocities (except close to zero) is high. Unfortunately, equation (2) is not suitable for speed $0.01 \mathrm{~m} \cdot \mathrm{s}^{-1}$, it is a situation of free convention, without forced drying. From equation (2) the coefficients $a, b$, for different velocities were obtained, what can also be seen in Table 1.

Using (1) the weight of the alfalfa samples during the drying process was calculated theoretically using equation (3): 


$$
m_{t}=\left(m-m_{d}\right) \cdot \exp \left[-\left(\frac{1}{b+1}\right) \cdot t^{b}\right]+m_{d},
$$

where $m_{t}$-theoretical weight of material at the time $t, \mathrm{~g}$.

The comparison of the theoretical and experimental data is shown in Figure 3. The most preferable form of the alfalfa sample drying coefficient with forced air was power expression: $K(t)=a t^{b}$. As it can be seen in Fig. 3, the theoretical model of the drying process well describes the values obtained in the experiment. The greatest difference was observed at the beginning of the process, which could be explained by the uneven distribution of moisture in the layer and the effect of moisture on the surface of the samples.

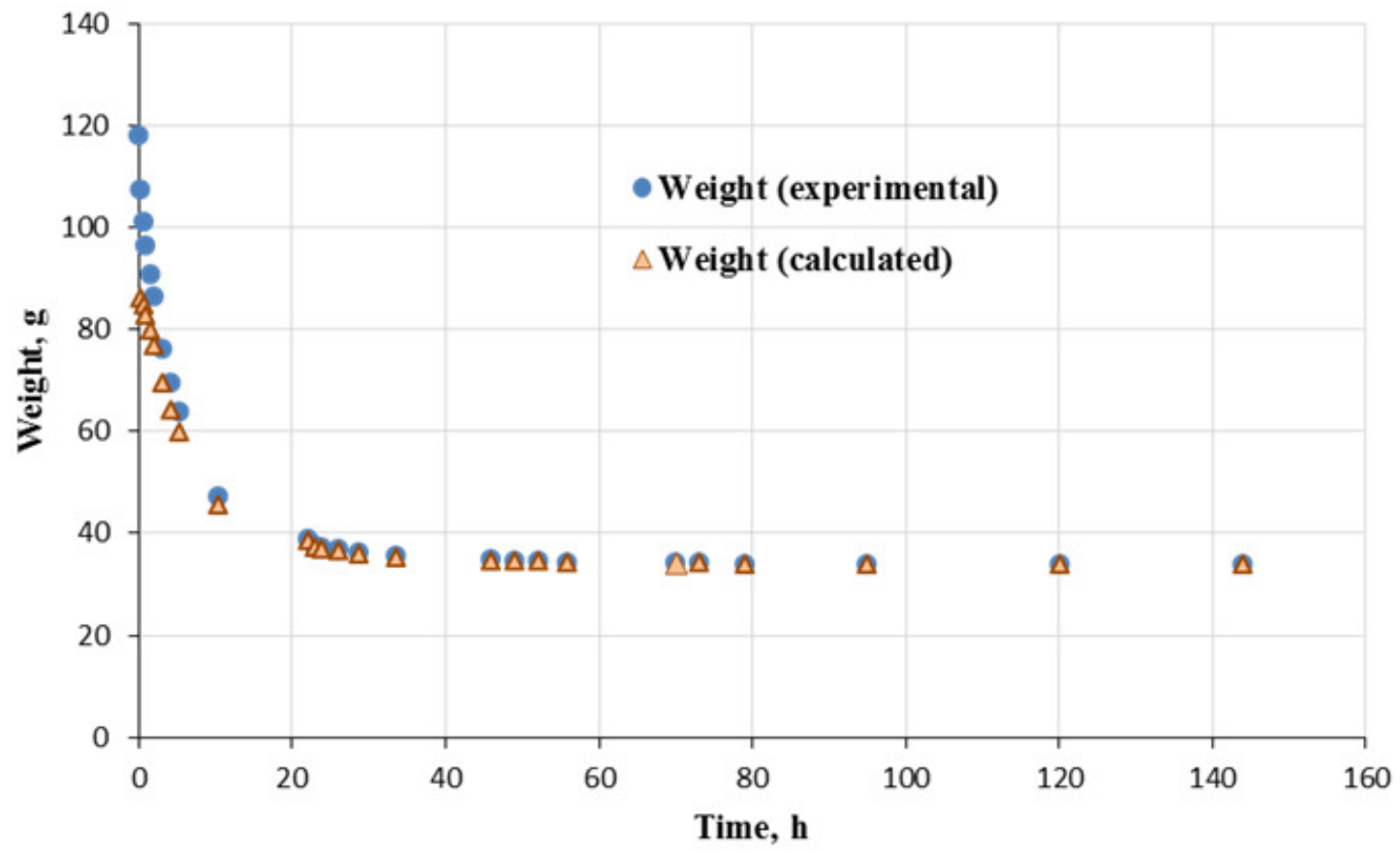

Fig. 3. Comparison of experimental and theoretical data. $m_{1}\left(v_{1}=1.20 \mathrm{~m} \cdot \mathrm{s}^{-1}\right)$

The experimental and theoretically calculated measurement difference is shown in Table 2 below. The mean absolute magnitude of the measurements and theoretical differences is mainly influenced by the differences observed during the first hours of the drying process. Moreover, the higher the air speed, the difference becomes smaller. This can be explained by the increased velocity of the drying process during increase of the drying agent (air) velocity.

Table 2

Absolute average differences between the experimental and the theoretically calculated weight at different drying air velocity

\begin{tabular}{|c|c|c|c|}
\hline \multicolumn{2}{|c|}{ Air velocity, ${\mathbf{~ m} \cdot \mathbf{s}^{-1}}^{-1}$} & Average, $\mathbf{g}$ & Standard deviation, $\mathbf{g}$ \\
\hline$v_{1}$ & 0.70 & 5.23 & 8.21 \\
\hline$v_{2}$ & 1.00 & 5.26 & 6.49 \\
\hline$v_{3}$ & 1.20 & 3.63 & 6.04 \\
\hline$v_{4}$ & 2.00 & 3.49 & 5.78 \\
\hline$v_{0}$ & 0.01 & 1.08 & 0.98 \\
\hline
\end{tabular}

Taking into account the results from Table 1, it is possible to find an expression that connects the parameters $\mathrm{a}$ and $\mathrm{b}$ of expression (2) with the speed of air in the drying process. A graph of the coefficients $a, b$ from Table 1, depending on the air velocities, was created, Fig. 4.

Again was found the mathematical equation of the dependencies of these two parameters in the form $(4,5)$. High coefficients of determination are obvious in Fig. 4. Changes of the coefficients $a, b$ can be counted from equations: 


$$
\begin{aligned}
& a=0.0319 \cdot \ln (v)+0.817, \\
& b=-0.04 \cdot \ln (v)-0.2794,
\end{aligned}
$$

where $v$ - velocity of drying air, $\mathrm{m} \cdot \mathrm{s}^{-1}$.

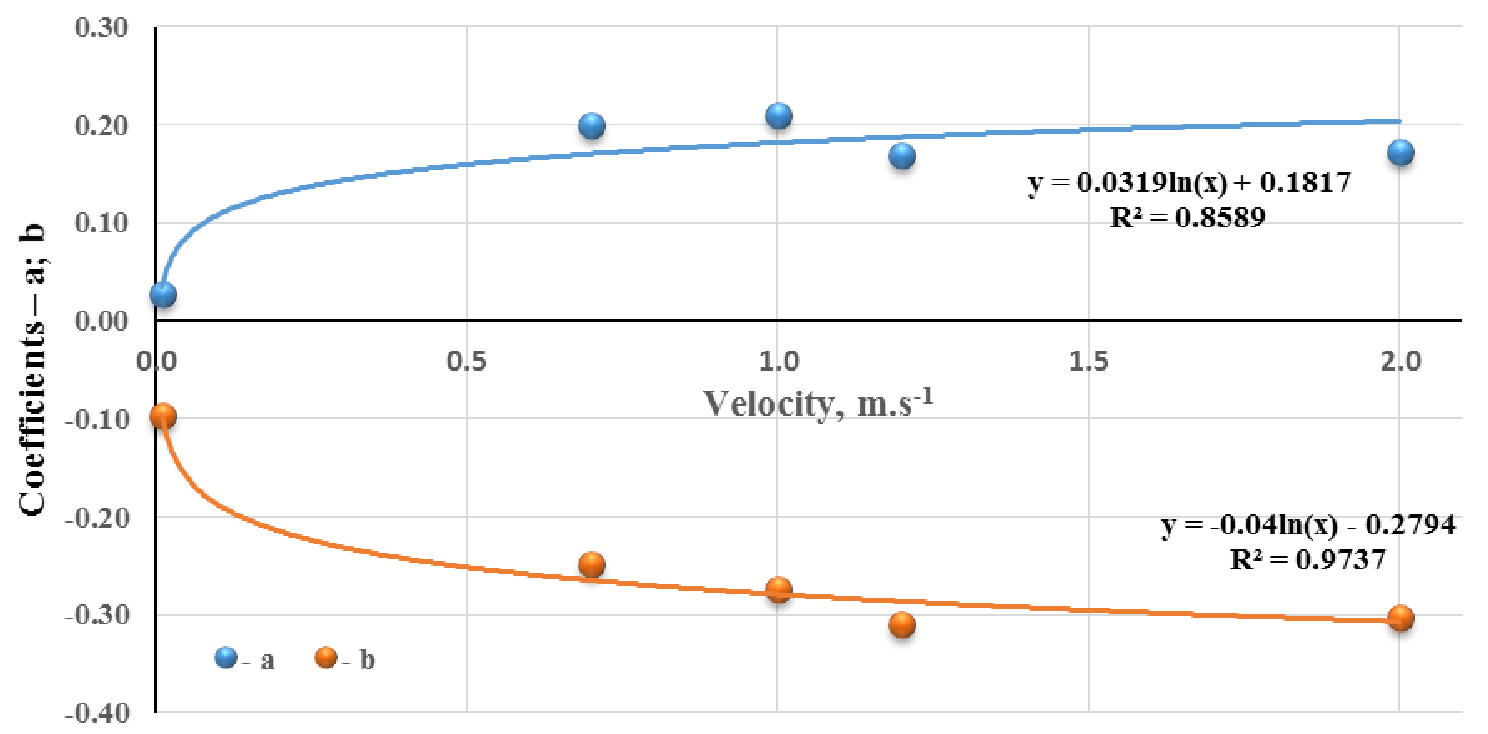

Fig. 4. Coefficients $a, b$ dependence from equation (2) on drying air velocity

If the velocity of the drying air is known, it is possible to expect $a, b$ and after that calculate the drying coefficient $K(t)$. Then we use the equation (3) to determine the weight of the alfalfa product at a certain drying time interval $t$. It should be noted that these expressions were obtained by drying with unheated air. By increasing the air temperature, the values of the constants will change, but the relationship can remain the same.

\section{Conclusions}

1. The most preferable form of determination of the alfalfa sample drying coefficient with forced air was power expression. Using the experimental data and the mathematical model of the thin layer drying process, it is possible to determine the unknown parameters at each speed of the drying agent.

2. The max average differences of experimental and theoretical weight values were lower than $6 \%$. The biggest difference was observed at lower air speeds and at the initial stage of the process.

3. The obtained relationships, which connect the parameters of the drying coefficient depending on the drying agent speed, allow predicting the process of drying at various speeds of unheated air. Drying time is one of main parameters, which could be determined as a practical result.

4. The theoretical background solved in this paper can be used for practical information about a suitable drying process of alfalfa for different conservation applications with economic benefits. The principles of the drying coefficient determination and optimization of the drying process can be applied for another type of fodder similar to alfalfa.

\section{References}

[1] Putnam D., Russelle M., Orloff S., Kuhn J., Fitzhurg L. Godfrey L., Kiess A., Long W. The Importance and Benefits of Alfalfa in the 21st Century: California Alfalfa and Forage Association, 2001, $24 \mathrm{p}$

[2] Lemus R. Hay storage: dry matter losses and quality changes. 2009 Mississippi State University 2009

[3] Anderson, P.M., Kjelgaard W.L., Hoffman L.D., Wilson L.L., Harpster H.W.. 1981.Harvesting practices and round bale losses. Trans. ASAE 24: pp. 841-842. 
[4] Rotz C.A., Abrams S.M. Losses and quality changes during alfalfa hay harvest and storage. Trans. ASAE 31, 1988: pp. 350-355.

[5] Rotz C. A., Davis R. J., Buckmaster, Allen M.S. Preservation of alfalfa hay with propionic acid. Applied Engineering in Agriculture 7(1), 1991. pp. 33-40.

[6] Shewmaker G.E. Hay preservation and storage losses Proceedings, Western States Alfalfa and Forage Symposium, Reno, NV, 2-4, 2015. 11 p.

[7] Rayburn E. Proper handling and curing of hay. Forage Manager. 2002., pp. 5811-5814.

[8] Holmes B. Dry round hay bale storage costs. Focus on Forage 6(5). 2004., pp. 1-3.

[9] Atzema A.J. A model for the drying of grass with real time weather data; Journal of Agricultural Engineering Research. 53, 1992, pp. 231-247.

[10] Bartzanas T., Bochtis D., Sorensen C., Sapounas A. \& Green O. A numerical modelling approach for biomass field drying. Biosystems Engineering. 2010. 106, pp. 458-469.

[11] Aboltins A., Kic P. Research in some medical plant drying process. Proceedings of 15th International Scientific Conference "Engineering for Rural Development". Jelgava, Latvia University of Agriculture, Latvia, 2016. pp. 121-125.

[12] Kaya A., Aydin O. An experimental study on drying kinetics of some herbal leaves. Energy Conversion and Management 2009. 50, pp. 118-124.

[13] Sokhansanj S., Patil R. Kinetics of dehydration of green alfalfa. Drying technology, 2007 pp. 1197-1234

[14] Wood H., Sokhansanj S.Heat treatment of chopped alfalfa in rotary drum dryers. Drying technology, 2010. pp. 543-569

[15] Kic P. Effect of different air velocities on convective thin-layer drying of alfalfa for livestock feeding Agronomy research 15(3) 2017. pp. 737-744.

[16] Kic P., Aboltins A. Convective drying of poultry manure by different air speeds. Proceedings of International Scientific Conference "Engineering for Rural Development". Jelgava, Latvia University of Agriculture, Latvia, 2013. pp. 121-125.

[17] Kic P., Liska R. Apparatus for drying loose or bulk materials. Utility model No. 23841. Prague: Industrial property Office, 2012.5 p. (In Czech)

[18] Aboltins A. Theoretical study of material drying coefficient; Engineering for Rural Development International Scientific Conference. 2013, pp. 153-158. 